\title{
High alkaline phosphatase activity and growth in preterm neonates
}

\author{
A LUCAS, O G BROOKE, B A BAKER, N BISHOP, AND R MORLEY \\ MRC Dunn Nutrition Unit and University Department of Paediatrics, Cambridge
}

SUMMARY In a study on 857 infants born preterm, high peak plasma alkaline phosphatase activity was independently related to slower growth rate in the neonatal period, and to a highly significant reduction in attained length at 9 months and 18 months post term. At 18 months the deficit in body length associated with peak neonatal plasma alkaline phosphase activity of $1200 \mathrm{IU} / 1$ or more was $1.6 \mathrm{~cm}(95 \%$ confidence interval 0.9 to $2.3 \mathrm{~cm})$ after adjusting for confounding factors. The strength and magnitude of this association between high plasma alkaline phosphase activity and body length was greater than that for any other factor identified, including the infant's sex and the presence of fetal growth retardation. Data are presented that support the view that the high plasma alkaline phosphatase activity reflected early bone mineral substrate deficiency resulting in metabolic bone disease.

We speculate that even silent early bone disease may interfere with the control of subsequent linear growth and emphasise the potential importance of providing preterm infants, especially those fed human milk, with adequate substrate for bone mineralisation.

Metabolic bone disease in preterm infants is common. ${ }^{1}$ Though this has often been described as 'rickets', current evidence suggests that in most cases it is caused by a deficiency of mineral substrate rather than of vitamin $\mathrm{D} .^{1-4}$ It is particularly common in very preterm infants who are being fed on breast milk. ${ }^{5}$ In most instances metabolic bone disease is not associated with obvious clinical signs, and the diagnosis has been based on radiographs, photonabsorptiometry, and biochemical changes including high plasma alkaline phosphatase activity. There is little information about whether such asymptomatic bone disease is benign or associated with an adverse outcome. Although there is evidence that linear growth is impaired in classical rickets, ${ }^{6}$ the effects of metabolic bone disease on growth performance in premature infants have not been sufficiently investigated.

Preterm infants fed their own mothers' milk have raised plasma alkaline phosphatase activity and reduced linear growth in comparison with formula fed babies, ${ }^{7}$ and there is a negative correlation between plasma alkaline phosphatase activity and linear growth at the age of 12 weeks in a small group of preterm infants ${ }^{8}$ : there are, however, no longer term studies of growth in relation to early evidence of metabolic bone disease.
In this paper we present such data in 857 infants from a large multicentre outcome study on the long term effects of early diet in low birthweight babies. This cohort has now been studied to 18 months corrected age.

\section{Patients and methods}

Infants from five centres (Cambridge, Ipswich, King's Lynn, Norwich, and Sheffield) who were participating in a larger multicentre trial of preterm infant feeding were studied. ${ }^{9}$ In all, 857 infants had sequential plasma alkaline phosphatase measurements made, and these are reported here. All infants weighed under $1850 \mathrm{~g}$ at birth, and the only exclusions were infants who died within 72 hours of birth and those with serious malformations known to impair growth or development. Parental consent was obtained in all cases, and approval was obtained from the local health authority ethics committees in each of the five centres.

Infants were randomly assigned to diet as described previously. ${ }^{9}$ Briefly, infants in three of the centres were assigned to receive banked donor breast milk or a preterm formula (Osterprem) as sole diets (trial1; $\mathrm{n}=140$ ) or as supplements to maternal milk (trial 2; $\mathrm{n}=308$ ). In the other two centres a standard full 
term adapted formula (Osterfeed) or preterm formula were used as sole diets (trial $3 ; n=156$ ) or as supplements to maternal milk (trial $4 ; n=253$ ). The preterm formula contained $35 \mathrm{mg}$ phosphorus and $75 \mathrm{mg}$ calcium $/ 100 \mathrm{ml}$. The full term formula contained $29 \mathrm{mg}$ phosphorus and $35 \mathrm{mg}$ calcium/ $100 \mathrm{ml}$. All infants received a minimum daily vitamin D intake of $800 \mathrm{IU}$. The median period (quartiles) to attainment of full enteral feeding was $8(6,12)$ days; and to discontinuation of the assigned diet $29(19,46)$ days. After this, infants were either fed by breast or on a standard 'term' infant formula and received 400 IU vitamin D daily until weaning.

The principal objective in this paper was to relate plasma alkaline phosphase activity to neonatal and later growth. Data on the effects of diet on plasma alkaline phosphatase activity and growth are included here only to add weight to the argument that high neonatal alkaline phosphatase activity reflects metabolic bone disease.

Extensive data were collected on obstetric, perinatal, and postnatal events, including the following growth measurements in the neonatal period: body weight (daily to the nearest $1 \mathrm{~g}$ on an electronic balance, Sartorius MP series); occipitofrontal head circumference (twice weekly to the next succeeding $1 \mathrm{~mm}$ using paper tape); and crown-heel length (once or twice weekly to the next succeeding $1 \mathrm{~mm}$ using a horizontal stadiometer). Weight gain $(\mathrm{g} / \mathrm{kg} /$ day) was calculated from the age when birth weight had been regained. Head growth and length gain were calculated by a similar analysis of measurements made over a period of at least two weeks after regaining birth weight.

Blood samples were drawn weekly at the time of routine monitoring from all infants during their stay in hospital. Plasma calcium concentrations were measured by atomic absorption spectrophotometry and phosphorus was determined by an end point method on $5 \mu \mathrm{l}$ of plasma using a direct phosphomolybdate reaction without deproteinisation (Smith, Kline Instrument Co Ltd). Alkaline phosphatase activity was measured kinetically on $2.5 \mu$ l plasma by the catalysed hydrolysis of p-nitro-phenylphosphate to p-nitrophenol and phosphoric acid (Roche Products Ltd).

All surviving infants from three centres (Cambridge, Ipswich, and King's Lynn) were invited for follow up examinations at 9 months post term, and children from all five centres were examined at 18 months post term. Measurements of weight, crown-heel length, and occipitofrontal head circumference were included at these examinations.

Statistical analysis was by the $\chi^{2}$ test, Student's $t$ test, and regression analysis.

\section{Results}

Details of the study population are shown in table 1 . The group has been divided into two according to peak plasma alkaline phosphatase activities $(\geqslant 1200 \mathrm{IU} / \mathrm{l})$. The value of $1200 \mathrm{IU} / \mathrm{l}$, was chosen because, as described below, this was shown to be the cut off point that best discriminated between two groups of infants in terms of their growth performance.

\section{ASSOCIATION BETWEEN INCREASED ALKALINE} PHOSPHATASE ACTIVITY AND EVIDENCE OF METABOLIC BONE DISEASE

We used sequential measurement of plasma alkaline phosphatase activity as an enzymatic marker of metabolic bone disease. Previously we conducted a survey in 26 infants (unpublished observations). That showed a highly significant correlation between a score for metabolic bone disease based on radiographic appearances, ${ }^{10}$ and maximum plasma alkaline phosphatase activity, confirming the findings of Glass et al that alkaline phosphatase activity is a

Table 1 Clinical details of study population; raw data have been divided according to peak alkaline phosphatase activity (up to, or above 1200 IUIl) during the neonatal period

\begin{tabular}{|c|c|c|c|}
\hline & \multicolumn{2}{|c|}{$\begin{array}{l}\text { Alkaline phosphatase } \\
\text { activity }\end{array}$} & \multirow[t]{2}{*}{ p Value } \\
\hline & $<1200$ IU/l & $\geqslant 1200 \mathrm{IU} / \mathrm{l}$ & \\
\hline \multirow{5}{*}{$\begin{array}{l}\text { Mean }(\text { SEM) birth } \\
\text { weight }(g) \\
\text { Mean }(\mathrm{SEM}) \text { gestation } \\
\text { (weeks) } \\
\text { Duration of ventilation: } \\
\text { No }(\%)<24 \text { hours } \\
(n=474) \\
\text { No }(\%) \geqslant 24 \text { hours } \\
(n=381)\end{array}$} & 1420 (11) & $1082(24)$ & $<0.001$ \\
\hline & $31.0(0.1)$ & $29.2(0.2)$ & $<0.001$ \\
\hline & & & \\
\hline & $427(90)$ & $47(10)$ & $<0.001$ \\
\hline & $298(78)$ & $83(22)$ & \\
\hline \multirow{4}{*}{$\begin{array}{l}\text { Sex: } \\
\text { No }(\%) \text { boys } \\
(n=425) \\
\text { No }(\%) \text { girls } \\
\quad(n=432) \\
\text { Weight for gestational } \\
\text { age: } \\
\text { No }(\%) \text { appropriate } \\
(n=567)\end{array}$} & & & \\
\hline & 357 (84) & $68(16)$ & $>0.5$ \\
\hline & $370(86)$ & $62(14)$ & \\
\hline & $485(86)$ & $82(15)$ & \\
\hline $\begin{array}{l}\text { No }(\%) \text { small for } \\
\text { gestational age } \\
(n=289)\end{array}$ & $241(83)$ & 48 (17) & $>0.4$ \\
\hline \multirow{3}{*}{$\begin{array}{l}\text { Pre-eclampsia: } \\
\text { No (\%) without } \\
(n=607) \\
\text { No (\%) with } \\
(n=240)\end{array}$} & & & \\
\hline & $519(86)$ & 40 (17) & $>0.4$ \\
\hline & $200(83)$ & 40 (17) & \\
\hline
\end{tabular}


Table 2 Association between peak plasma alkaline phosphatase activity and incidence of hypophosphataemia, low urinary phosphorus concentration, and hypercalcaemia

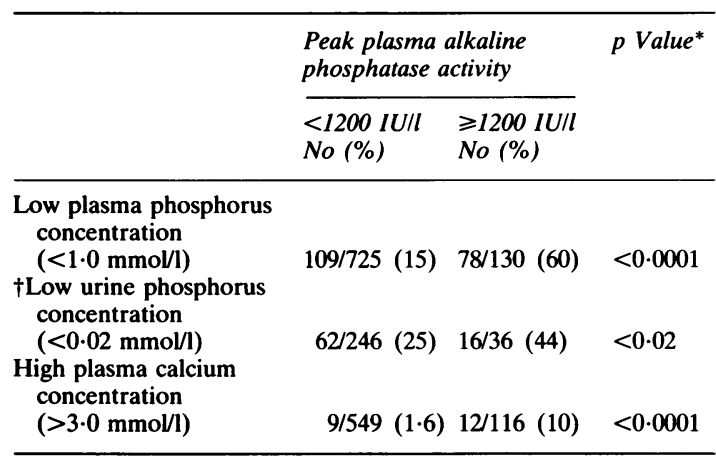

${ }^{*} \chi^{2}$ test, Idf; testimates made on only. a segmental subsample.

satisfactory measure of active metabolic bone disease in such studies. ${ }^{11}$ We provide here further strong evidence that high plasma alkaline phosphatase activity was related to bone mineral substrate deficiency.

Analysis of raw data showed that infants with high peak plasma alkaline phosphatase activity $(\geqslant 1200 \mathrm{IU} / \mathrm{l})$ had a higher incidence of low plasma and urinary phosphorus concentrations (minimum recorded values less than $1.0 \mathrm{mmol} / 1$, and $0.02 \mathrm{mmol} / 1$, respectively), and a higher incidence of hypercalcaemia (peak plasma calcium concentration more than $3.0 \mathrm{mmol} / \mathrm{l})$, each suggesting low phosphorus intake or phosphorus deficiency (table 2). These

Table 3 Effect of donor breast milk or preterm formula, assigned randomly (as sole diets or supplements to maternal expressed milk), on the incidence of high peak plasma alkaline phosphatase values, hypophosphataemia, and low or high urinary phosphorus concentrations

\begin{tabular}{llll}
\hline & $\begin{array}{l}\text { Donor breast } \\
\text { milk } \\
\text { No }(\%)\end{array}$ & $\begin{array}{l}\text { Preterm } \\
\text { formula } \\
\text { No }(\%)\end{array}$ & p Value \\
\hline $\begin{array}{l}\text { High plasma alkaline } \\
\text { phosphatase activity } \\
(>1200 \mathrm{IU} / \mathrm{l})\end{array}$ & $57 / 226(25)$ & $31 / 222(14)$ & $<0.01$ \\
$\begin{array}{l}\text { Low plasma phosphorus } \\
\text { concentration } \\
(<1.0 \mathrm{mmol} / \mathrm{l})\end{array}$ & $49 / 153(32)$ & $27 / 155(17)$ & $<0.01$ \\
$\begin{array}{c}\text { Low urine phosphorus } \\
\text { concentration } \\
(<0.02 \mathrm{mmol} / \mathrm{l})\end{array}$ & $39 / 78(50)$ & $16 / 70(23)$ & $<0.001$ \\
$\begin{array}{l}\text { High urine phosphorus } \\
\text { concentration } \\
(>3 \text { mmol/l) }\end{array}$ & $1 / 78(1.3)$ & $16 / 70(23)$ & $<0.0001$ \\
\hline
\end{tabular}

${ }^{*} \chi^{2}, 1$ df. associations were still significant $(p<0.05)$ after using logistic regression to adjust for birth weight, gestation, duration of ventilatory assistance, and fetal growth retardation.

In the randomised comparison of infants fed donor breast milk or preterm formula (as sole diets or supplements to maternal milk; trials 1 and 2 combined), those fed banked milk with its lower content of phosphorus and calcium had a higher incidence of high plasma alkaline phosphatase activity (table 3). Fig 1 shows that in infants weighing under $1500 \mathrm{~g}$ (the high risk group for bone disease) plasma alkaline phosphatase values remained consistently higher in infants fed donor milk than in those fed a preterm formula throughout the first nine weeks postpartum. High alkaline phosphatase activity in infants fed human milk was associated with a higher incidence of hypophosphataemia and low urinary phosphorus values in this group (table 3).

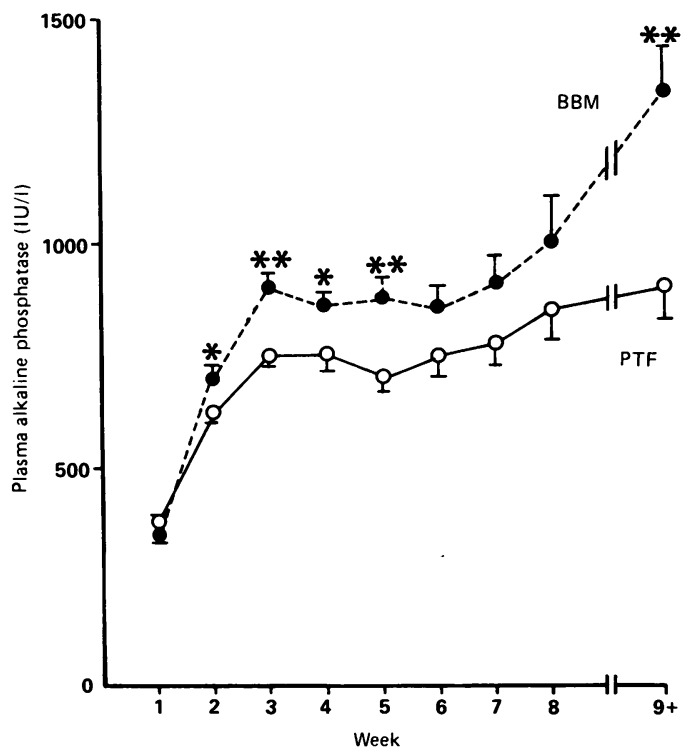

Fig 1 Mean (SEM) plasma alkaline phosphatase activity from week 1 to week 9 and beyond in infants weighing under $1500 \mathrm{~g}$ at birth, according to diet. Infants were randomly assigned to banked breast milk $(B B M)$ or preterm formula (PTF) as sole diets or supplements to their mother's own milk, Sample size at week 1 for BBM was 129 and for $P T F 126$, falling respectively (as the infants were discharged or died) to 101 and 95 at week 4 and to 36 and 19 at week 9 and beyond; ${ }^{*} p<0.05 ;{ }^{* *} p<0.01$. 

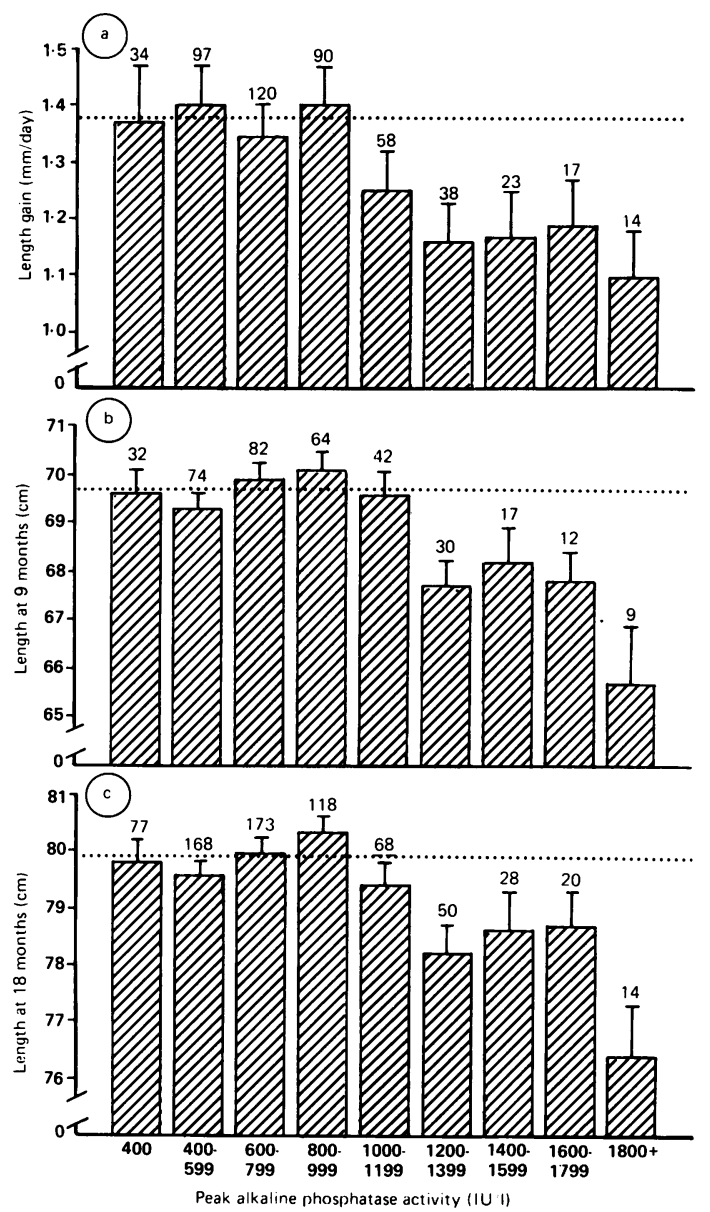

Fig 2 Association between peak plasma alkaline phosphatase activity and (a) rate of neonatal length gain (b) length at 9 months corrected age and (c) length at 18 months corrected age. The horizontal line represents the mean value for length gain or length at 9 or 18 months in all infants whose peak alkaline phosphatase value was $<1000$ IU/l (first four data bars of each group).

ASSOCIATION BETWEEN INCREASED PLASMA ALKALINE PHOSPHATASE ACTIVITY AND GROWTH

Growth was assessed in the neonatal period as weight gain $(\mathrm{g} / \mathrm{kg} /$ day), length gain $(\mathrm{mm} / \mathrm{day})$, and head circumference gain ( $\mathrm{mm} / \mathrm{day})$. Body weight $(\mathrm{kg})$, length $(\mathrm{mm})$, and head circumference $(\mathrm{mm})$ were recorded at 9 months in three of the five centres, and at 18 months in all centres. The 719 subjects seen at 18 months represented a $94 \%$ follow up rate among survivors.

The principle outcome of interest in this study was linear growth. Analysis of raw data (fig 2) indicated that there was no trend in neonatal length gain or in length at 9 at 18 months with increasing peak alkaline phosphatase activities up to $1000 \mathrm{IU} / \mathrm{l}$. When values were above this, linear growth and later body length were lower with the most dramatic reductions seen in babies with peak alkaline phosphatase activites of over $1200 \mathrm{IU} / \mathrm{l}$.

In table 4 raw data are presented for these growth variables according to whether or not peak alkaline phosphatase exceeded $1200 \mathrm{IU} / \mathrm{l}$. In the group of infants with high peak plasma alkaline phosphatase activity, gains in weight, length, and head circumference were significantly reduced in the neonatal period. At 9 and 18 months body length and body weight, though not head circumference, were significantly lower.

These comparisons of raw data are confounded by other differences (including those shown in table 1) between infants with high and low alkaline phosphatase activities, which could contribute to differences in growth performance. We therefore constructed a series of regression models, each of which included one of the above growth variables as the dependent variable; independent variables were plasma alkaline

Table 4 Association between high plasma alkaline phosphatase activity (peak value $>1200$ IU/l), growth in the neonatal period, and anthropometric indices at 9 and 18 months (corrected post term age). Data expressed as mean (SEM)

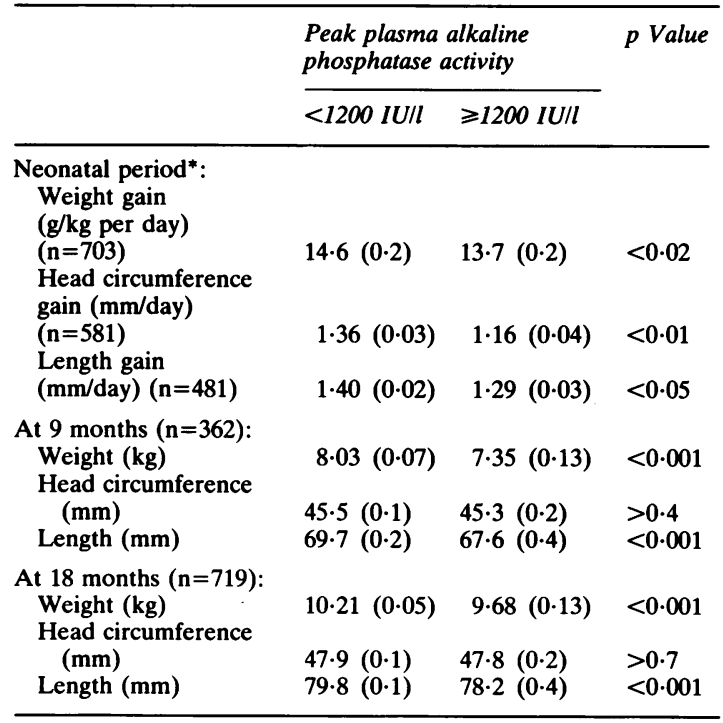

*Number of subjects analysed for weight, head circumference, and length gain were the number for whom more than three data points had been collected over at least two weeks beyond the age of regaining birth weight. 
phosphatase activity (either as a continuous or dichotomous variable), together with birth weight, gestation, fetal growth retardation (above or below 10th centile of birth weight for gestation), sex, days of ventilation, and days in oxygen (expressed as logarithm, plus 1 to avoid $\log 0$ ), number of fetuses (singletons or twins/triplets) and maternal hypertension. As a further independent variable, diet (exclusively fed human milk or not) was added to the models.

Plasma alkaline phosphatase activity was initially entered into these models as a continuous variable to assess its relationship, after adjusting for potentially confounding factors, with neonatal length gain, and body length, at 9 or 18 months. Though there was a significant linear relationship between increasing peak alkaline phosphatase activity and two of these growth variables (neonatal length gain, $p<0.01$, and length at 18 months, $p<0.0005$ ), there was a better fit using a quadratic regression, with the square of peak alkaline phosphatase activity relating significantly to length gain $(p<0.01)$, length at 9 months $(p<0.01)$, and length at 18 months $(p<0.0001)$. Nevertheless, from further modelling, and inspection of the raw data in fig 3, we observed a dramatic reduction in neonatal length gain and in body length at 9 or 18 months in infants whose peak alkaline phosphatase was above 1000 IU/l. This justifies treating peak alkaline phosphatase activity as a dichotomous variable. Using a variety of cut off values, significant relationships between peak alkaline phosphatase and all three of the linear growth outcome variables was found for cut off values between $900 \mathrm{IU} / 1$ and $1350 \mathrm{IU} / \mathrm{l}$; the best modelled cut off for predicting outcome, however (taking both the size of the regression coefficient and significance into account) was for a cut off at $1200 \mathrm{IU} / \mathrm{l}$ (as suggested also by the data in fig 3). In subsequent analysis this value of $1200 \mathrm{IU} / \mathrm{l}$ was used to divide infants into those with 'high' or 'low' peak alkaline phosphatase activities.

In the neonatal period (up to the time of discharge) the only factors among those included in the regression model that were independently related to length gain were high alkaline phosphatase activity $(\mathrm{p}<0 \cdot 01)$, and diet $(<0 \cdot 05)$, both of which seemed to have a small additional association with linear growth independent of its relationship with

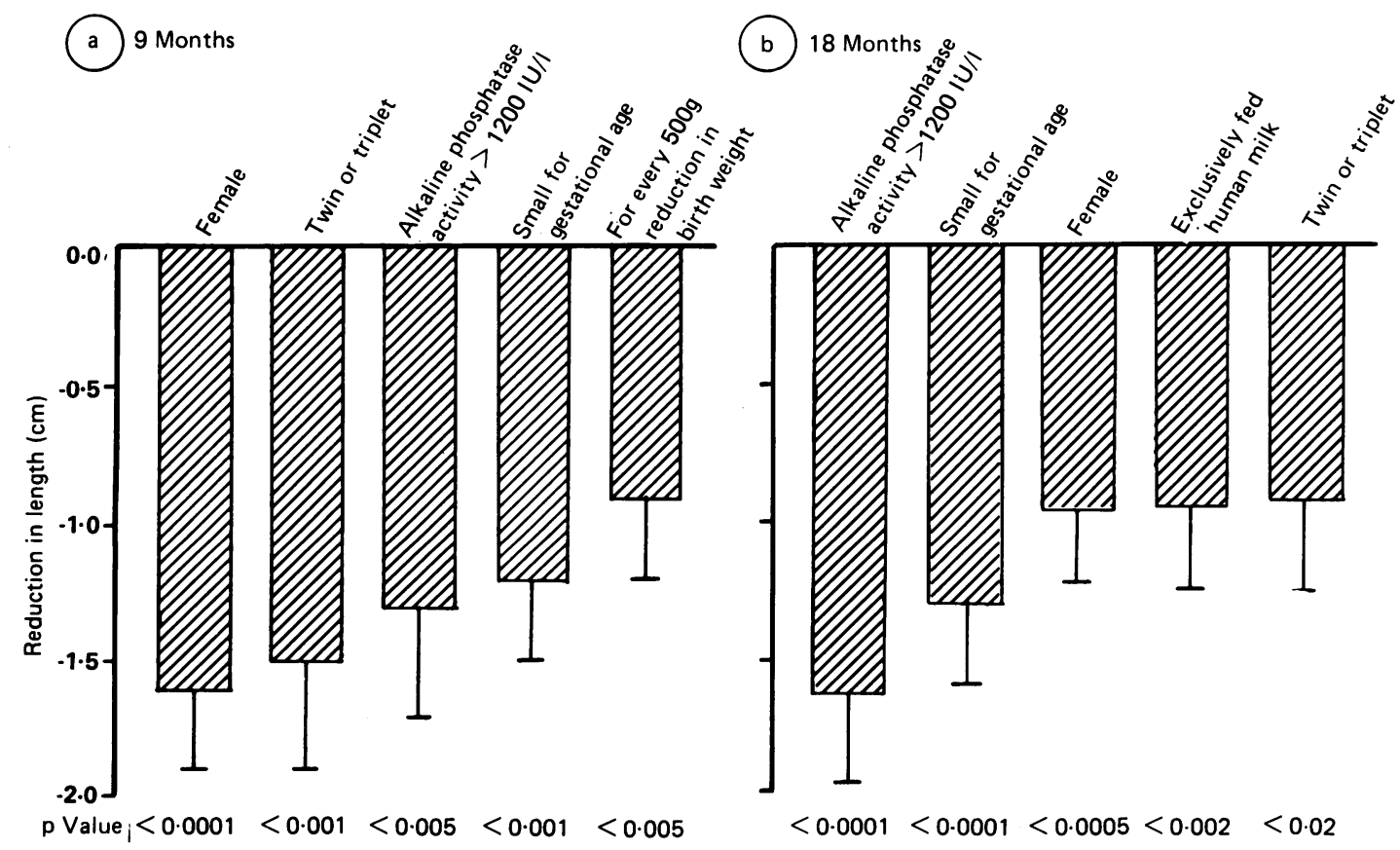

Fig 3 Factors independently associated with reduced body length at (a) 9 months and (b) 18 months' after term. The magnitude (regression coefficient) of the associations and standard errors depicted were derived from a regression model constucted for each age group, with body length as the dependent variable. 
bone disease. The reduction in length gain in infants with a plasma alkaline phosphatase activity of $1200 \mathrm{IU} / \mathrm{l}$ or more was $1.4 \mathrm{~mm} /$ week ( $95 \%$ confidence interval (CI) $0 \cdot 4$ to $2 \cdot 4$ ).

At 9 months the reduction in body length associated with an alkaline phosphatase of $1200 \mathrm{IU}$ or more, after adjusting for the other factors in the model, was $1.3 \mathrm{~cm}(95 \% \mathrm{CI} 0.4$ to $2.2 \mathrm{~cm})$; other factors in the model independently related to reduced body length at 9 months were female sex, low birth weight, and being small for gestational age, or a twin. The magnitude of these associations are shown in fig 3 (a).

At 18 months the association between high neonatal alkaline phosphatase activity and reduced attained length was stronger and of greater magnitude than any other factor identified, which included being female, small for gestational age, or a twin. There was also an association between shorter stature and being fed on human milk in the neonatal period, which seemed to be independent of the association between diet and early bone disease. These associations are shown graphically in fig 3 (b).

The magnitude of the reduction in body length at 18 months associated with a peak neonatal alkaline phosphatase activity of $1200 \mathrm{IU} / \mathrm{l}$ or more was $1.6 \mathrm{~cm}$ (95\% CI 0.9 to $2.3 \mathrm{~cm})$.

When adjustment was made for confounding factors there was no significant association between high alkaline phosphatase activity and gain in weight or head circumference in the newborn period, though there was a strong trend towards a negative association with weight gain, nor was any association with body weight or head circumference found at 9 and 18 months.

\section{Discussion}

High neonatal plasma alkaline phosphatase activity in low birthweight infants was strongly associated with impaired linear growth (reduced length gain in the neonatal period) and, of most importance, smaller attained length at 9 and 18 months corrected age. After adjusting for a wide range of potentially confounding factors, high neonatal plasma alkaline phosphatase activity (1200 IU/l or more) emerged as the major factor relating to stature at 18 months. At this age the deficit in length associated with high plasma alkaline phosphatase activity was $1.6 \mathrm{~cm}$, corresponding to more than half a standard deviation for body length in healthy 18 month old children.

Other factors shown to be independently associated with length at 9 or 18 months were sex, being small for gestational age, or a twin (or triplet). There was also an independent association between reduced attained length at 18 months and exclusive human milk feeding, even after adjusting for the effect of this diet on the incidence of metabolic bone disease. Thus for either sex, singleton infants who were an appropriate weight for gestation, fed on a formula, and with a peak plasma alkaline phosphatase activity of less than $1200 \mathrm{IU} / \mathrm{l}$, has a mean length at 18 months close to the 50th centile. In contrast, infants falling into the opposite categories, were estimated to be nearly $4 \mathrm{~cm}$ shorter (fig 2), with a mean length near the third centile for an infant born at full term. Maternal pre-eclampsia, which has been reported to cause congenital rickets ${ }^{12}$ was not found to be associated with reduced linear growth. This does not rule out, however, an important effect of pre-eclampsia on neonatal mineral homoeostasis and later growth. Such an effect might be entirely subsumed into the effect of being small for gestational age.

A significant association between high alkaline phosphatase activity and reduced short and longer term linear growth was found whether peak alkaline phosphatase was treated as a continuous variable or a dichotomous one. More detailed analysis, however, showed minimal change in linear growth with peak alkaline phosphatase values up to $1000 \mathrm{IU} / \mathrm{l}$, and a precipitous reduction in linear growth if the peak alkaline phosphatase activity was above $1200 \mathrm{IU} / \mathrm{l}$. Thus we suggest that, for prognostic purposes, it is most useful to treat alkaline phosphatase as a dichotomous variable with 'high' and 'low' values above and below $1200 \mathrm{IU} / \mathrm{l}$.

It is important to consider what a raised plasma alkaline phosphatase activity means, as doubt has been thrown on its value as an indicator of metabolic bone disease in low birthweight infants. ${ }^{13}{ }^{14}$ Such doubts have been mainly concerned with its specificity as an indicator of active bone disease at a particular point in an infant's clinical course, and several workers have found values that were not grossly increased at times when there was radiological evidence of frank bone disease. ${ }^{13} 1516$

The biology of alkaline phosphatase has been reviewed by Anderson. ${ }^{17}$ The enzyme is located on the membrane of osteoblast derived 'matrix vesicles', and in parent osteoblasts is close to the mineralisation front. Current evidence suggests that membrane phosphatase is a phosphotransferase, which transfers phosphate residues into matrix vesicles, wheretogether with trapped calcium ions-they initiate crystallisation. As mineralisation proceeds, both membrane vesicles and osteoblasts are disrupted, and it may be mainly at this stage that alkaline phosphatase leaks into the circulation. Extrapolating from data from Anderson, working on phosphate depleted rats (unpublished observations) we hypo- 
thesise that when bone mineral substrate is deficient an adaptive increase in synthesis or activity of alkaline phosphatase occurs, resulting in greatly increased plasma activity despite reduced bone mineralisation. Certainly it would not be surprising if the complex events leading to increased alkaline phosphatase activity in the plasma were not precisely related in time to structural evidence of bone mineral deficiency. Nevertheless, when grossly elevated, plasma alkaline phosphatase activity in neonates is predominantly of bone origin ${ }^{18}$ and there are abundant data to show that its activity is usually increased during frank metabolic bone disease, often exceeding the maximum adult value several fold. ${ }^{11}{ }^{13-16}$ 19-22 It is increased when bone mineral intake is inadequate and growth is slowed. ${ }^{2723-26}$ Many workers have regarded raised plasma alkaline phosphatase activity as an important indicator of metabolic bone disease, ${ }^{11} 162127$ and in particular when sequential monitoring is undertaken. ${ }^{16}$ Conversely, a reduction in plasma alkaline phosphatase activity has been observed during catch up growth following periods of slow growth in preterm infants. ${ }^{8}$

Our data add further weight to the view that high plasma alkaline phosphatase activity is associated with bone mineral substrate deficiency. In a randomised comparison infants fed human milk had significantly higher plasma alkaline phosphatase activity than those receiving a formula providing twice the calcium and phosphorus contents of breast milk (fig 1). The human milk fed group showed further evidence of phosphorus depletion, with a significantly higher incidence of hypophosphataemia and low urine phosphorus concentrations. Moreover, high alkaline phosphatase activity itself was associated with hypophosphataemia, low urinary phosphorus concentrations, and an increased incidence of hypercalcaemia, which has been described with phosphorus depletion. 2829

Regardless of the debate on whether high plasma alkaline phosphatase activity is a valuable neonatal screening test for metabolic bone disease in individual preterm infants, we have shown that it is an important indicator of outcome in terms of later linear growth. Few previous studies have related early bone disease to long term outcome; work in this field has focused mainly on identification and quantification of active bone disease. Metabolic bone disease in preterm infants, however, is usually asymptomatic and is frequently missed. Indeed, in this investigation high plasma alkaline phosphatase activity often occurred when the baby was well, and might have been overlooked had the infant not been taking part in a scientific study. We suggest poor linear growth performance both in the short and longer term could be viewed as an important, adverse, clinical outcome response to even silent early metabolic bone disease. We speculate also that the trend towards reduced neonatal weight gain seen with increased plasma alkaline phosphatase activity is linked to the effects of phosphorus depletion on soft tissue growth and metabolism. ${ }^{30}$ Though we have shown that high alkaline phosphatase activity relates well to these adverse responses, it is pertinent to note that other tests for metabolic bone disease, namely radiographs of long bones and photonabsorptiometry, as yet have unknown predictive value for later outcome. Furthermore, radiography and densitometry both include irradiation of the patient.

Our hypothesis, strongly supported by the data presented, that neonatal metabolic bone disease has a long lasting and important effect on linear growth, is perhaps a surprising one as excellent catch up is usually seen during the treatment of classical rickets. ${ }^{31}$ Early bone disease in preterm infants seems increasingly unlikely to be a vitamin $\mathrm{D}$ related problem in most cases ${ }^{1}$ so cannot be directly compared with classical rickets. Even so, if we assume that the cause of metabolic bone disease in primarily a deficiency of bone mineral substrate, it still requires explanation that catch up growth and a return to normal growth velocity do not apparently take place once calcium and phosphorus intake and absorption have reached normal infant values ${ }^{32}$ and the bones have remineralised. ${ }^{33}$

We have considered that our findings could be explained by some completely different and as yet unidentified confounding factor or factors that were associated with early bone disease and had a continued influence on growth. Arguably it is difficult to adjust statistically for the variable degree of illness seen in preterm infants. We used days of ventilation and days in oxygen as such indicators. Though these measures (especially days of ventilation) have proved to be sensitive markers of poor longer term prognosis for other outcome measures in this cohort (for example neurodevelopment ${ }^{34}$ ), interestingly we found here that requirement for respiratory support was unrelated to linear growth up to 18 months after adjustment was made for other factors such as birth weight, fetal growth retardation, and twinning. Alternatively, we suggest that early metabolic bone disease itself may interfere with the control mechanisms for subsequent linear growth. This might occur either as a direct consequence of the bone disease itself, or because of the secondary effects such disease may have on the hormonal milieu during a critical growth period normally protected in the intrauterine environment. Indeed, it is possible that any process that results in 
lasting retardation of linear growth at an earlyperhaps critical-stage could have an adverse 'programming' or 'imprinting' effect on later linear growth performance. In this regard it is worth considering the serious effect on long term linear growth that may occur in infants who have been born stunted at term after prolonged placental insufficiency. ${ }^{35}$ Our data presented here indicate an independent detrimental effect of fetal growth retardation on linear growth to 18 months.

We suggest that even entirely subclinical metabolic bone disease may have prolonged consequences for growth performance. Though our future planned follow up of this cohort will be important in assessing the longer term significance of our observations, at present it would seem prudent to make every effort to achieve an optimal intake of bone mineral substrate in the neonatal period. This cannot be achieved with unsupplemented human milk.

We wish to thank Drs MFM Bamford, JFB Dossetor, AW Boon, RG Pearse, and PM Crowle for their assistance in the neonatal units at Ipswich, King's Lynn, Sheffield, and Norwich, and also Farley Health Products for financial assistance.

\section{References}

${ }^{1}$ Brooke OG, Lucas A. Metabolic bone disease in preterm infants. Arch Dis Child 1985;60:682-5.

2 Rowe J, Rowe D, Horak E, et al. Hypophosphatemia and hypercalciuria in small premature infants fed human milk: evidence for inadequate dietary phosphorus. J Pediatr 1984;104: 112-7.

${ }^{3}$ Chan GM, Mileur L, Hansen JW. Effects of increased calcium and phosphorus formulas and human milk on bone mineralization in preterm infants. J Pediatr Gastroenterol Nutr 1986;5:444-9.

${ }^{4}$ Gross SJ. Bone mineralization in preterm infants fed human milk with and without mineral supplementation. $J$ Pediatr 1987;111:450-8.

5 McIntosh N, Livesay A, Brooke OG. Plasma 25-hydroxyvitamin $\mathrm{D}$ and rickets in infants of extremely low birthweight. Arch Dis Child 1982;57:848-50.

${ }^{6}$ Stearns G, Jeans PC, Vandecar V. The effect of vitamin D on linear growth in infancy. J Pediatr 1936;9:1-10.

7 Cooper PA, Rothberg AD, Davies VA, Argent AC. Comparative growth and biochemical response of very low birthweight infants fed own mother's milk, a premature infant formula, and one of two standard formulas. J Pediatr Gastroenterol Nutr 1985;4:786-94.

8 James JA, Mayne PD, Barnes IC, Kovar IZ. Growth velocity and plasma alkaline phosphatase activity in the preterm infant. Early Hum Dev 1985;11:27-32.

${ }^{9}$ Lucas A, Gore SM, Cole TJ, et al. Multicentre trial on feeding low birthweight infants: effects of diet on early growth. Arch Dis Child 1984;59:722-30.

${ }^{10}$ Pohlandt F. A radiological sign of bone demineralization in preterm infants. Klin Padiatr 1985;197:155-6.

$"$ Glass EJ, Hume R, Hendry GM, Strange RC, Forfar JO. Plasma alkaline phosphatase activity in rickets of prematurity. Arch Dis Child 1982;57:373-6.

12 Zeidan S, Bamford M. Congenital rickets with maternal preeclampsia. J R Soc Med 1984;77:426-7.

13 McIntosh N, Williams JE, Lyon AJ, Wheeler KA. Diagnosis of rickets of prematurity. Lancet 1984 ;ii:869.
14 James JR, Congdon PJ, Truscott J, Horsman A, Arthur R. Osteopenia of prematurity. Arch Dis Child 1986;61:871-6.

15 Koo WW, Gupta JM, Nayaner VV, Wilkinson M, Posen A. Skeletal changes in preterm infants. Arch Dis Child 1982;57: 447-52.

16 Walters EG, Murphy JF, Henry P, Gray OP, Elder GH. Plasma alkaline phosphatase activity and its relation to rickets in preterm infants. Ann Clin Biochem 1986;23:652-6.

17 Anderson HC. Matrix vesicle calcification: review and update. In: Peck WA, ed. Bone and mineral research 3. Amsterdam: Elsevier, 1985:109-49.

18 Brooke OG, Brown IRF, Bone CDM, et al. Vitamin D supplements in pregnant Asian women: effects on calcium status and fetal growth. Br Med J 1980;280:751-4.

19 Kovar IZ, Mayne P, Wallis J. Neonatal rickets in one of identical twins. Arch Dis Child 1982;57:792-4.

20 Chudler AE, Brown DR, Holzman IR, Oh KS. Nutritional rickets in two very low birthweight infants with chronic lung disease. Arch Dis Child 1980;55:687-90.

${ }^{21}$ Kovar IZ, Mayne P, Barltrop D. Plasma alkaline phosphatase activity: a screening test for rickets in preterm neonates. Lancet 1982;i:373-6.

22 Callenback JC, Sheehan MB, Abramson SJ, Hall RT. Etiologic factors in rickets of very low-birthweight infants. $J$ Pediatr 1981;98:800-5.

${ }^{23}$ Eek S, Gabrielsen LH, Halvorsen S. Prematurity and rickets. Pediatrics 1957;20:63-77.

${ }^{24}$ Schanler RJ, Garza C, O'Brien Smith E. Fortified mother's milk for very low birthweight infants: results of macromineral balance studies. J Pediatr 1985;107:767-74.

25 Hillman LS, Hoff NH, Salmons S, Martin L, McAlister W, Haddad J. Mineral homeostasis in very premature infants: serial evaluation of serum 25 -hydrocyvitamin $D$, serum minerals, and bone mineralization. J Pediatr 1985;106:970-80.

${ }^{26}$ Pettifor JM, Stein H, Herman A, Ross FP, Blumenfield T, Moodely GP. Mineral homeostasis in very low birthweight infants fed either own mother's milk or pooled pasteurized preterm milk. J Pediatr Gastroenterol Nutr 1986;5:248-53.

27 Hillman LS, Salmons SJ, Slatopolsky E, McAlister WH. Serial serum 25-hydroxyvitamin $D$ and mineral homeostasis in very premature infants fed preterm human milk. $J$ Pediatr Gastroenterol Nutr 1985;4:762-70.

${ }^{28}$ Miller RR, Menke JA, Mentser MI. Hypercalcemia associated with phosphate depletion in the neonate. J Pediatr 1984;105: 814-7.

${ }^{29}$ Lyon AJ, McIntosh N, Wheeler K, Brooke OG. Hypercalcaemia in extremely low birthweight infants. Arch Dis Child 1984;59: $1141-4$.

30 Wharton BA. Nutrition and feeding of preterm infants. Oxford: Blackwell, 1987:117-132.

${ }^{31}$ Hess AF. Rickets including osteomalacia and tetany. London: Henry Kimpton, 1930: 401-29.

32 Salle B, Senterre J, Putet G, Rigo J. Effects of calcium and phosphorus supplementation on calcium retention and fat absorption in preterm infants fed pooled human milk. J Pediatr Gastroenterol Nutr 1986;5:638-42.

33 Chan GM, Mileu LJ. Post hospitalization growth and bone mineral status of normal preterm infants. Am J Dis Child 1985;139:896-8.

34 Lucas A, Morley R, Cole TJ. Adverse neurodevelopmental outcome of moderate neonatal hypoglycaemia. $\mathrm{Br}$ Med $\mathrm{J}$ 1988;297:1304-8.

35 Neligan GA, Kolvin I, Scott DM, Garside RF. Born too soon or born too small. Clinics in developmental medicine No 61 . London: Heineman, 1976:54-60.

Correspondence to Dr A Lucas, Dunn Nutritional Laboratory, Downhams Lane, Milton Road, Cambridge CB4 1XJ.

Accepted 10 February 1989 